\title{
Memory Strategies in Children with Learning Disabilities ${ }^{1}$
}

\author{
Richard S. Newman and John W. Hagen \\ University of Michigan
}

\begin{abstract}
Memory strategies were examined among children, 7-13 years old, with diagnosed learning disabilities, in order to investigate whether they perform in appropriately active and efficient ways. The children were grouped at two age levels and administered tasks of serial recall and free recall. A strategy-training session was conducted on the second task. On the serial recall, neither age group showed evidence of rehearsal, in contrast to previous studies. On the free recall task, the younger children's performance was consistent with the mediation deficiency hypothesis, while the older children improved in sorting, clustering, and recall following training; i.e., they showed a typical production deficiency. There was support for considering this sample of learning disabled children as inactive learners, with potential for developmental change. Serial recall improved with age, and the older children's production deficiencies in free recall appeared to be ameliorated with training in organizational strategies.
\end{abstract}

Research on the short-term memory performance of children with learning difficulties has shown a marked increase in recent years (e.g., see Torgesen \& Kail, in press). In comparing them with normal learners, Torgesen (1977b) speculated that children classified as learning "disabled" often may, in fact, be better viewed as inactive or inefficient learners, with underlying abilities intact. Support for this contention has come from separate studies of both serial and free recall, in which the strategies of verbal rehearsal and category clustering, respectively, have been investigated. These two tasks, serial and free recall, are both employed in the present study to further study the developmental progression of performance within a sample of children with learning disabilities.

\footnotetext{
'Joseph Price, Director of the University of Michigan Fresh Air Camp, and Lynne Cook, Assistant to the Director, collaborated on this project, and their contributions are gratefully acknowledged.

Reprint requests should be sent to Dr. John W. Hagen, Developmental Psychology, 3433 Mason Hall, University of Michigan, Ann Arbor, Michigan 48109.
} 
It has been inferred from the findings of a number of studies with 8 - to 10 -year olds with learning disabilities that inadequate use is made of rehearsal strategies during serial recall. These studies have found among learning disabled children either no primacy effect at all (Tarver, Hallahan, Kauffman, \& Ball, 1976; Torgesen \& Goldman, 1977) or lower primacy performance for the learning disabled children (Bauer, 1977; 1979). Additionally, Torgesen (1977a) has provided direct observational data of ineffective encoding activity during ordered recall for fourth grade learning disabled children. Around the age of ten years, a primacy effect that is comparable to that of non-learning disabled children does emerge (Tarver, et al., 1976), providing evidence that the developmental description of these children is one of delay in the use of active rehearsal, and hence later-than-normal facilitation of short-term memory and selective attention.

Recency recall has also been examined in the studies above. There do not appear to be any age differences in response to sensory store demands (see Atkinson \& Shiffrin, 1968) among learning disabled children at least eight years old, as inferred from their performance on the last one or two items of serial recall (Bauer, 1977; 1979). Further, there do not appear to be differences in recency recall between these children and children without learning disabilities. This can be taken as an indication of the structural integrity of learning disabled children's memory (see Hagen \& Stanovich, 1977).

One purpose of the present study is to replicate these previous findings; most importantly, of rehearsal among older, but not younger learning disabled children.

In contrast to the established developmental picture of learning disabled children's lag in the use of verbal rehearsal in serial recall, evidence is lacking concerning how these same children come to employ organizational strategies in free recall.

Free recall of categorizable items has been shown to be facilitated through organization, and this facilitation increases with normal development (Moely, 1977). Among learning disabled children of $81 / 2$ - to 11 -years old, a deficiency in the ability to take advantage of input organization, in the form of conceptual categories among lists of words, has been shown (Parker, Freston, \& Drew, 1975). Bauer (1979) found that among 9 - and 10-year old children, the learning disabled clustered and recalled less than non-disabled groups in a task of free recall of categorizable words.

Torgesen (1977a) has shown differences between fourth grade learning disabled and non-disabled children in their tendency to sort pictures into categories during study time prior to free recall, as well as differences in their actual recall. However, clustering during recall did not differ between the two groups in this study. Torgesen also demonstrated the effectiveness of training in eliminating relatively poor organizational strategy-use and recall among those learning disabled children. Failure to engage spontaneously in efficient goal-directed activity which the children were capable of doing, i.e., a production deficiency, 
seemed to characterize them as it does normal performance of younger, nonlearning disabled children (e.g., Moely, Olson, Halwes, \& Flavell, 1969).

Although not dealing with the specific issue of learning difficulty, Paris (1978) stresses the distinction between mediation and production deficiencies: in the former, a strategy might be spontaneously employed and may even be further trained, but its use does not facilitate recall. A production deficiency refers to a potentially facilitative strategy capability not being employed, or coordinated, for the purpose of attaining some goal. Transitions from mediation deficiency to production deficiency, and from production deficiency to full production, characterize normal memory development (see Flavell, 1970; Hagen, Jongeward, \& Kail, 1975). The same progression, perhaps delayed developmentally, may characterize learning disabled children.

In spite of a number of studies comparing organization in free recall in learning disabled children with non-disabled children, there have not been studies that examine the use of organizational strategies developmentally within a group of children with learning disabilities. A major purpose of this study, then, is to assess usage of an appropriate strategy and to provide training in that usage, among children who are at an age where strategy employment should be emerging. Rehearsal in serial recall is examined among the same children in order to test for the generality of describing them as "inactive" or deficient in strategy use on episodic memory tasks.

\section{METHOD}

\section{Subjects}

The children were recruited through a summer residential educational program at the University of Michigan's Fresh Air Camp. All children originally included in the study had been clinically diagnosed by their schools as having learning disabilities. None had physical or sensory disabilities, and none had been diagnosed as being emotionally impaired.

According to the Wechsler Intelligence Scale for Children-Revised (WISC-R), only children within the normal range of intelligence were included, and as a result there were a total of 38 subjects. Among these, full-scale WISC-R scores ranged from 85 to 124 , with a mean of $100(S D=9)$. The children's general levels of intelligence were taken into account in the study in order to help identify developmental patterns in the two experimental tasks. A median split on IQ produced a group with equal to- or under-100 IQ $(n=20)$ and a group with over-100 IQ $(n=18)$.

The children's academic deficiency, as reported by their schools, was checked in an attempt to verify, to some degree, homogeneity in the sample. Reading and arithmetic ratios were computed, based on the ratio of achievement 
(as measured by the Peabody Individual Achievement Test, PIAT) to mental age (as calculated from the WISC-R). Ratios, or learning quotients (see Johnson \& Myklebust, 1964), of .90 or less were defined as deficient. Both the PIAT and the WISC-R were administered at the Camp to assure maximum recency and reliability of test scores. Twenty-one of the 38 children $(55 \%)$ were deficient in both academic areas. Ten had low reading ratios alone $(26 \%)$, and seven were low in arithmetic alone $(19 \%)$.

There were 33 boys and 5 girls in the sample. Chronological ages of the children ranged from 7 to 13.8 years, with a mean of 10.3 years $(S D=2.0)$. A median split on age produced a group of 7 - to 10 -year olds $(n=20)$ and a group of 11- to 13-year olds $(n=18)$.

\section{Materials and Procedures}

For the serial recall task, horizontal arrays of seven pairs of pictures were presented one at a time (for details, see Hagen \& Kingsley, 1968). Each pair contained an animal and a household object, and children were instructed to attend to only the household objects. A cue card is shown at the end of each trial, and the task is to point to the picture in the face-down array that matches it. Two tests are made at each of the serial positions; i.e., there are 14 trials in all. Performance is measured both by the total number of pictures the child recalls correctly (the central score, which is out of 14) and by the serial position of the pictures recalled. In addition, the child is asked which animal had been paired with each of the household objects. The number correct here (out of seven) constitutes the incidental score. For the serial position analysis, primacy was defined as recall on the first two positions, and recency was at the last two positions.

For the free recall task, 25 picture cards were used, with five pictures falling into each of five categories, e.g., animals, fruits, tools, clothing, and parts of the body. After a practice trial for familiarization, all 25 are shown together in a mixed arrangement, and a three-minute study period is provided during which time the child may move or rearrange the pictures in any way he/she wishes. Then the child is asked to recall as many of the pictures as possible. Following this initial trial, there was a training session in which the child was instructed in physically sorting pictures into categories, studying the pictures in these smaller groups, and recalling them one group at a time. Then a new set of 25 pictures (from five new categories) was presented, along with a reminder to sort, study, and recall by groups. Following the study period, recall was assessed. This was followed by a second post-training trial, with 25 new pictures (from five new categories) but with no accompaniment of reminders concerning strategy usage.

The following data were obtained for each of the three trials: (a) total free recall, (b) sorting of items by categories during the study period, and (c) cluster- 
ing of items by category during the recall. Reviews by Moely (1977), Murphy, Campione, and Puff (1977), and Murphy (1979) were referred to concerning the appropriateness of various measures for evaluating clustering. Following the suggestion of Colle (1972), two different measures were employed as a check on their convergence, in terms of independence of list length or total recall. They were the Item Clustering Index, ICI (see Robinson, 1966), and the Ratio of Repetition, RR (see Cohen, Sakoda, \& Bousfield, 1954).

\section{RESULTS}

Initial analyses of variance showed no sex differences on any of the measures, so all 38 subjects were pooled together in subsequent analyses. ANOVAs were also performed in order to see if there was any differentiation in performance according to the academic area(s) in which the subjects showed their learning difficulty. There were no significant differences.

\section{Serial Recall}

Figure 1 illustrates the mean proportions of central recall for both age groups as a function of serial position. Heterogeneity of variance across positions, as reported by Bauer $(1977,1979)$, was not a problem here. Data were analyzed by a 2 (Age of subject) $\times 2$ (IQ of subject) $\times 7$ (Serial position) analysis of variance, with the last factor as a repeated measures variable. This analysis resulted in a main age effect $[F(1,32)=10.10, p<.01]$, a main effect for serial position $[F(6,192)=9.41, p<.01]$, and no interaction or IQ effects (means in Figure 1 are collapsed across IQ levels). The older children showed greater overall central recall than the younger, and recall at the last several positions appeared greater than at earlier positions.

Although recall at the first two positions did increase with increasing age (these two simple main effect comparisons were made with a Bonferroni test with $p<.05$ maintained over four position comparisons in all), there was no evidence of a primacy effect in relation to the other positions among either age group. This latter observation was supported by Scheffé $95 \%$ simultaneous confidence intervals about the contrast between the two primacy positions and the middle three positions. Hence, even the children in this sample who were over 10 years old did not have elevated performance at the primacy positions. This finding is in contrast to the performance of the older learning disabled children of comparable age in Tarver et al . (1976), with whom rehearsal in serial recall was in evidence.

Figure 1 shows a significant recency effect for both age groups when recall at the last two positions is compared to the middle three positions $(p<.05$ with Scheffé tests). The simple main effect comparisons, across ages, of recall at the last two positions' showed that the older children recalled more items than the 


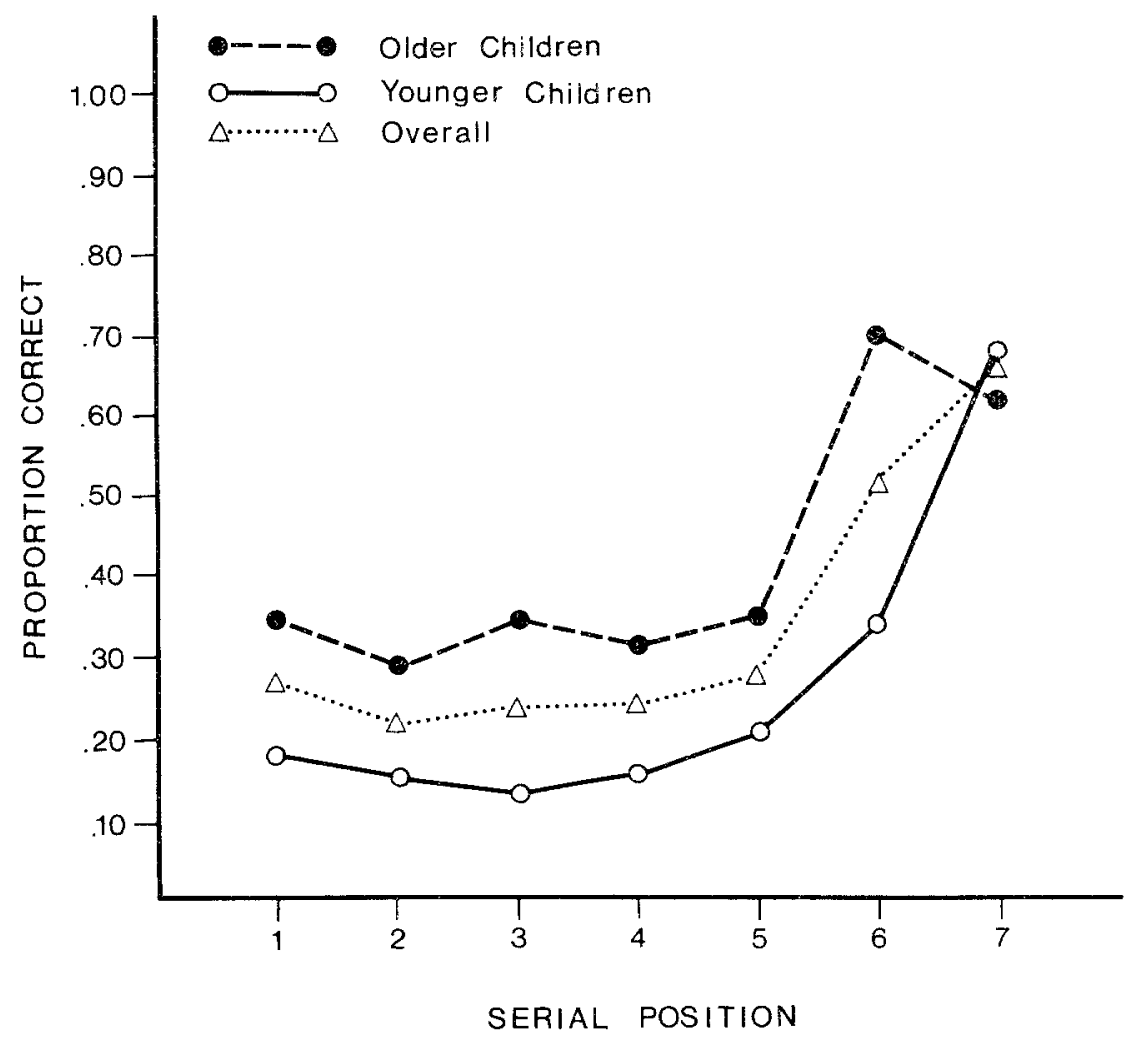

Figure 1. Central recall as a function of serial position and age.

younger did at the sixth position $(p<.05)$, but not at the last. Based upon their last-position recency effects, the younger learning disabled children did not exhibit sensory store performance any lower than that of the older children. Incidental recall showed no significant relationship with age. This was consistent with the findings of Tarver et al. (1976) and Tarver, Hallahan, Cohen, and Kauffman (1977), in which incidental recall did not decline among learning disabled children until age 15 .

The older children among this sample of learning disabled children performed better at serial recall than the younger. However, apparently this difference was due neither to an increased use of rehearsal nor to a difference in attention to the incidental, potentially distracting, stimuli.

\section{Free Recall}

Analysis of variance was the principal statistical test used for the free recall task. Simultaneous planned comparisons among means were carried out to investigate 
hypothesized age and training contrasts, with the Bonferroni technique used as protection from Type I error. The Scheffé technique was used for post hoc examination of any interaction contrasts. Three sets of data are presented: total number of items recalled, item sorting during the study period, and item clustering during the recall period. Both the Item Clustering Index (ICI) and the Ratio of Repetition (RR) were analyzed as clustering indices for both the study and recall periods. They produced similar results; both are referred to subsequently unless differentiation is noted.

Number of Items Recalled. A three-way ANOVA (Age $\times$ IQ $\times$ Repeated trials) of the total number of items recalled showed that there was a main age effect $(p<.01)$, but no significant effects due to trial or IQ (see Table 1 ). In Figure 2 and Table 2 the cell means are presented, with data collapsed across IQ levels.

Overall, training did not significantly improve the total number of items recalled. Group means progressed from 12.2 items (out of 25) before training to only 12.9 and 12.8 items after training. However, for the older children, recall increased from 13.6 to 16.3 and 16.0 items, whereas the corresponding recall for the younger children was $10.8,9.8$, and 9.9 items. It appeared, then, that the older children recalled more than the younger, especially on Trial 2 . An interaction was suggested in the ANOVA $[F(2,68)=2.30, p=.108$ for the age $\times$ trial

\section{TABLE 1}

ANOVA Results Indicating Age, IQ, and Trial Main Effects and Interactions

\begin{tabular}{lrrr}
\hline & $f$ & $d f$ & $p<$ \\
\hline Recall: & & & \\
Age & 23.89 & 1,34 & .000 \\
IQ & 1.09 & 1,34 & \\
Trial & .46 & 2,68 & \\
Age $\times$ Trial & 2.30 & 2,68 & \\
Sorting: & & & \\
Age & 8.64 & 1,34 & .006 \\
IQ & .51 & 1,34 & \\
Trial & 42.93 & 2,68 & .000 \\
Age $\times$ Trial & 1.20 & 2,68 & \\
Clustering (ICI): & & & \\
Age & 44.21 & 1,34 & .000 \\
IQ & 2.30 & 1,34 & \\
Trial & 13.21 & 2,68 & .000 \\
Age $\times$ Trial & 5.15 & 2,68 & .008 \\
Clustering (RR) & & & \\
Age & 24.18 & 1,34 & .000 \\
IQ & 1.85 & 1,34 & \\
Trial & 11.22 & 2,68 & .000 \\
Age $\times$ Trial & 2.28 & 2,68 & \\
\hline
\end{tabular}




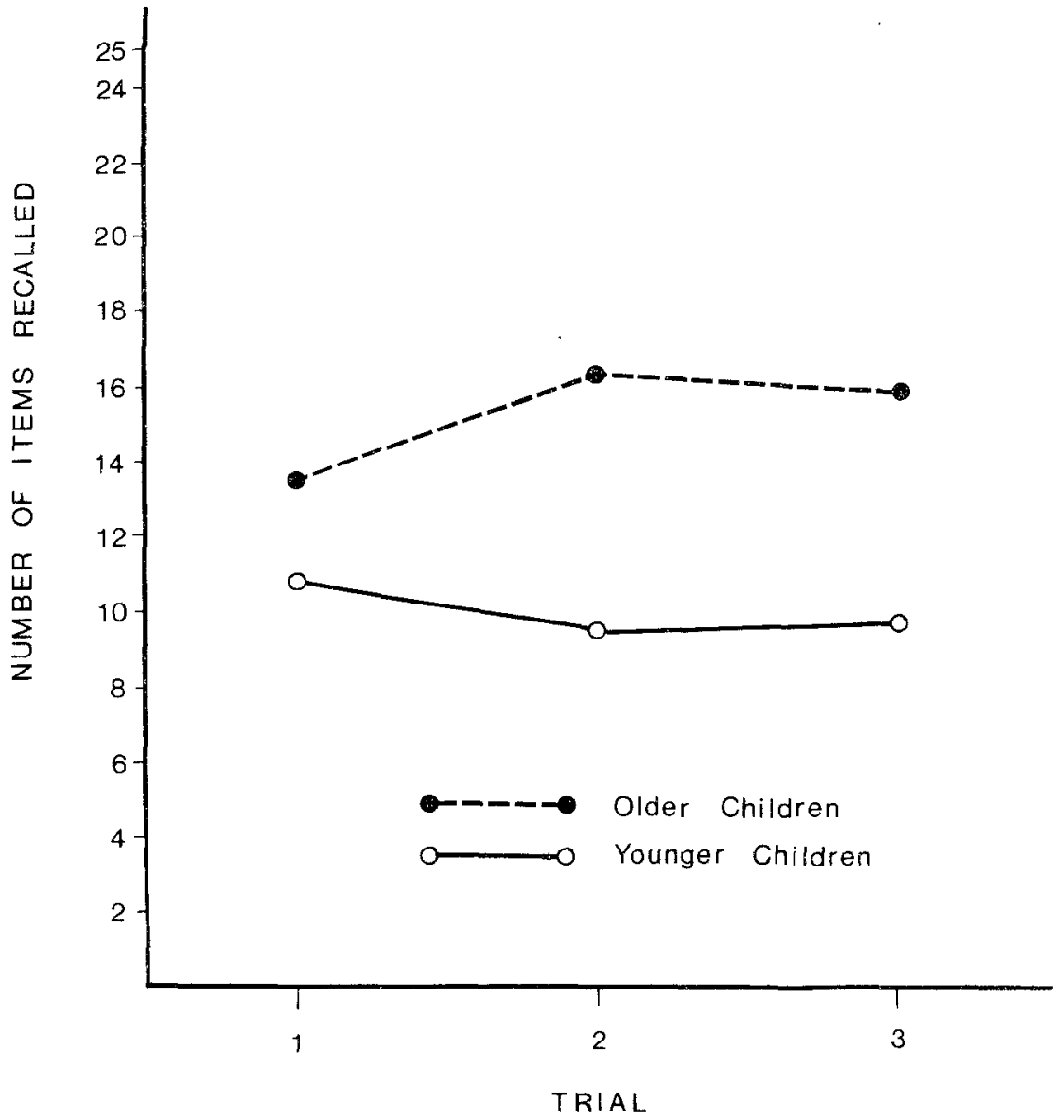

Figure 2. Number of items recalled as a function of trial and age.

interaction], because of the difference in the Trial 1-to-Trial 2 change in recall between the two age groups.

Looking at recall differences between ages, at each trial, the individual comparisons were significant $(p<.05)$ at Trial 2 and Trial 3 , but not at Trial 1 (see Table 2). Six matched pair comparisons involving training effects were also carried out at a Bonferroni $95 \%$ simultaneous confidence level. The contrast among the older children, from Trial 1-to-Trial 2, approached significance $[t(17)$ $=2.10, p<.10]$.

Whereas there was an overall age effect, it was only after training that the older children recalled significantly more than the younger. Age did seem to play a role in the extent to which instructions facilitated performance. 
TABLE 2

Means (and Standard Deviations) of Free Recall Measures with Results of Simultaneous Planned Comparisons

between the Two Age Groups

\begin{tabular}{|c|c|c|c|c|c|c|}
\hline & \multicolumn{6}{|c|}{ Trial } \\
\hline & \multicolumn{2}{|l|}{1} & \multicolumn{2}{|l|}{2} & \multicolumn{2}{|l|}{3} \\
\hline & $\bar{x}$ & $t(34)$ & $\bar{x}$ & $f(34)$ & $\bar{x}$ & $t(34)$ \\
\hline \multicolumn{7}{|c|}{ Number of Items Recalled } \\
\hline \multirow[t]{2}{*}{ Young } & $10.8(3.2)$ & & $9.8(5.7)$ & & $9.9(4.3)$ & \\
\hline & & 1.48 & & $3.48^{* *}$ & & $3.25^{* *}$ \\
\hline Old & $13.6(4.5)$ & & $16.3(4.2)$ & & $16.0(5.6)$ & \\
\hline \multicolumn{7}{|l|}{ Sorting } \\
\hline \multirow[t]{2}{*}{ Young } & $.24(.39)$ & & $.70(.36)$ & & $.74(.39)$ & \\
\hline & & .79 & & $2.29 * \star \star$ & & $2.05^{* * *}$ \\
\hline Old & $.34(.46)$ & & $.99(.02)$ & & $1.00(.00)$ & \\
\hline \multicolumn{7}{|c|}{ Clustering (ICl) } \\
\hline \multirow[t]{2}{*}{ Young } & $.26(.18)$ & & $.36(.24)$ & & $.33(.20)$ & \\
\hline & & 1.60 & & $4.78^{*}$ & & $5.51^{*}$ \\
\hline Old & $.37(.22)$ & & $.69(.21)$ & & $.71(.21)$ & \\
\hline \multicolumn{7}{|c|}{ Clustering (RR) } \\
\hline \multirow[t]{2}{*}{ Young } & $.43(.22)$ & & $.57(.28)$ & & $.50(.20)$ & \\
\hline & & 1.09 & & $3.13^{\star \star}$ & & $4.06^{* *}$ \\
\hline Old & $.50(.20)$ & & $.77(.07)$ & & $.76(.11)$ & \\
\hline
\end{tabular}

Sorting. It should be noted that for sorting during the study period, there is no computational difference between the ICI and the RR indices. Analyzing these data, a three-way ANOVA showed both an age $(p<.01)$ and a trial effect $(p<.01)$, and no IQ effect (see Table 1 and Figure 3$)$. The mean measure of sorting rose from .29 (out of 1.00 ) before training to .84 and .86 after training. In other words, overall the older children sorted more than the younger, and overall, training seemed to increase the exhibition of the strategy.

It would appear from Figure 3 that there was some tendency toward an interaction between age and trial, i.e., that the older children sorted more than the younger, especially on Trials 2 and 3 . Although this observation was not borne out in the ANOVA, this was probably because of a ceiling effect on the older children's scores on Trials 2 and 3. There was support for this argument from the individual comparisons of sorting, between ages, at each trial. There was no difference between ages at Trial 1; however, the difference at Trial 2 and Trial 3 showed a tendency toward more sorting being used among the older children (see Table 2). Six matched pair comparisons involving training effects showed that, for both age groups, there was a significant increase in sorting from both Trial 1-to-Trial 2 and Trial 1-to-Trial $3[t(19)=4.96$ and $t(19)=3.89$, for 


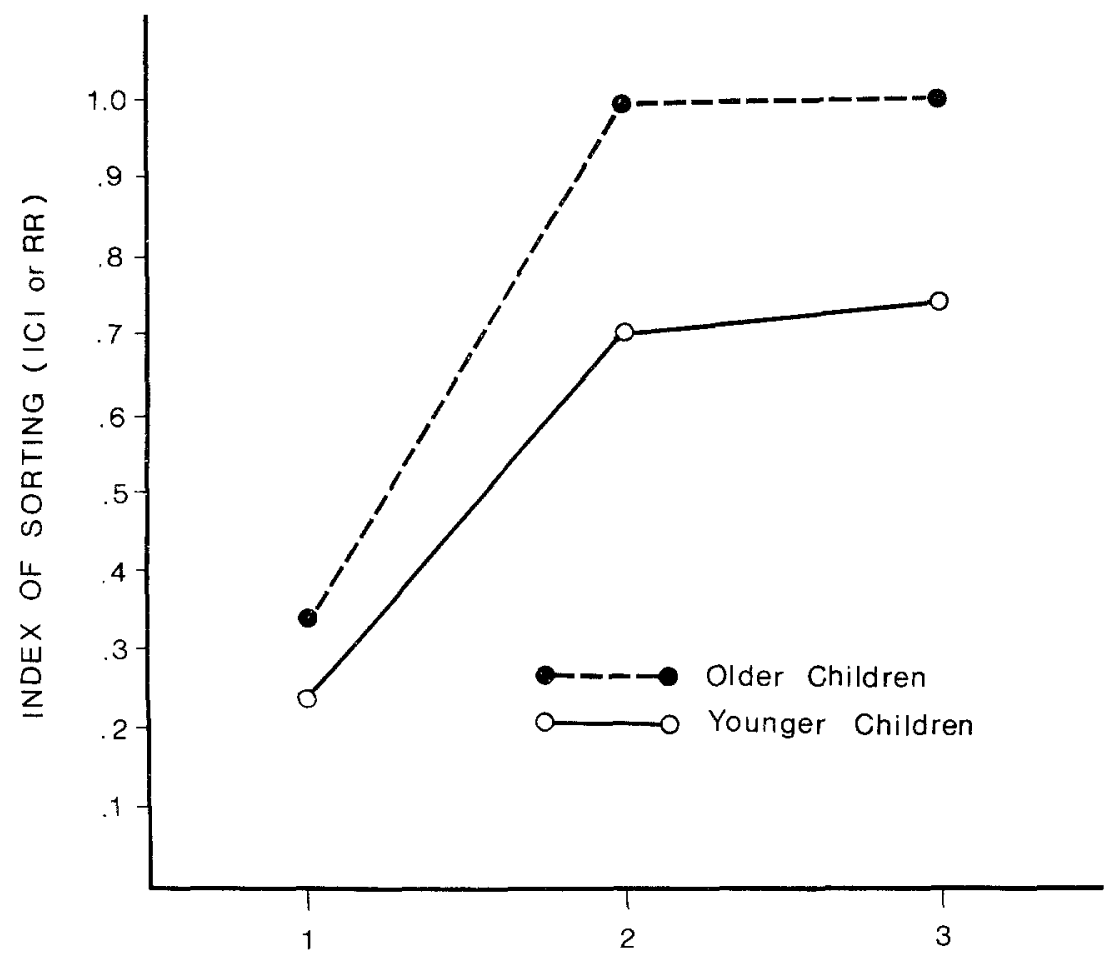

TRIAL

Figure 3. Use of sorting during study period as a function of trial and age.

the younger, and $t(17)=6.12$ and $t(17)=6.11$, for the older, all $p$ 's $<.01]$. For both groups, strategy use did not change on the third trial, when the children were left on their own $[t(19)=.38$ and $t(17)=1.06$, both $p$ 's n.s. $]$.

Whereas there were both age and trial effects on the sorting, there seemed to be an age-differential in facilitation from training. It was with training that the older children's sorting increased to the extent that there was evidence of an overall age effect.

Clustering. For clustering scores during recall, the pattern was similar to that found for sorting during the study period, but here the interaction was significant in the three-way ANOVA of the ICI measure. An age effect $(p<$ $.01)$, a trial effect $(p<.01)$, and an age $\times$ trial interaction $(p<.01)$ were found; again there was no IQ effect (see Table 1 and Figure 4 ). The mean ICI measure increased from .31 (out of 1.00 ) before training to .52 and .51 after training. Two interaction contrasts were significant (using Scheffé 95\% simultaneous confi- 


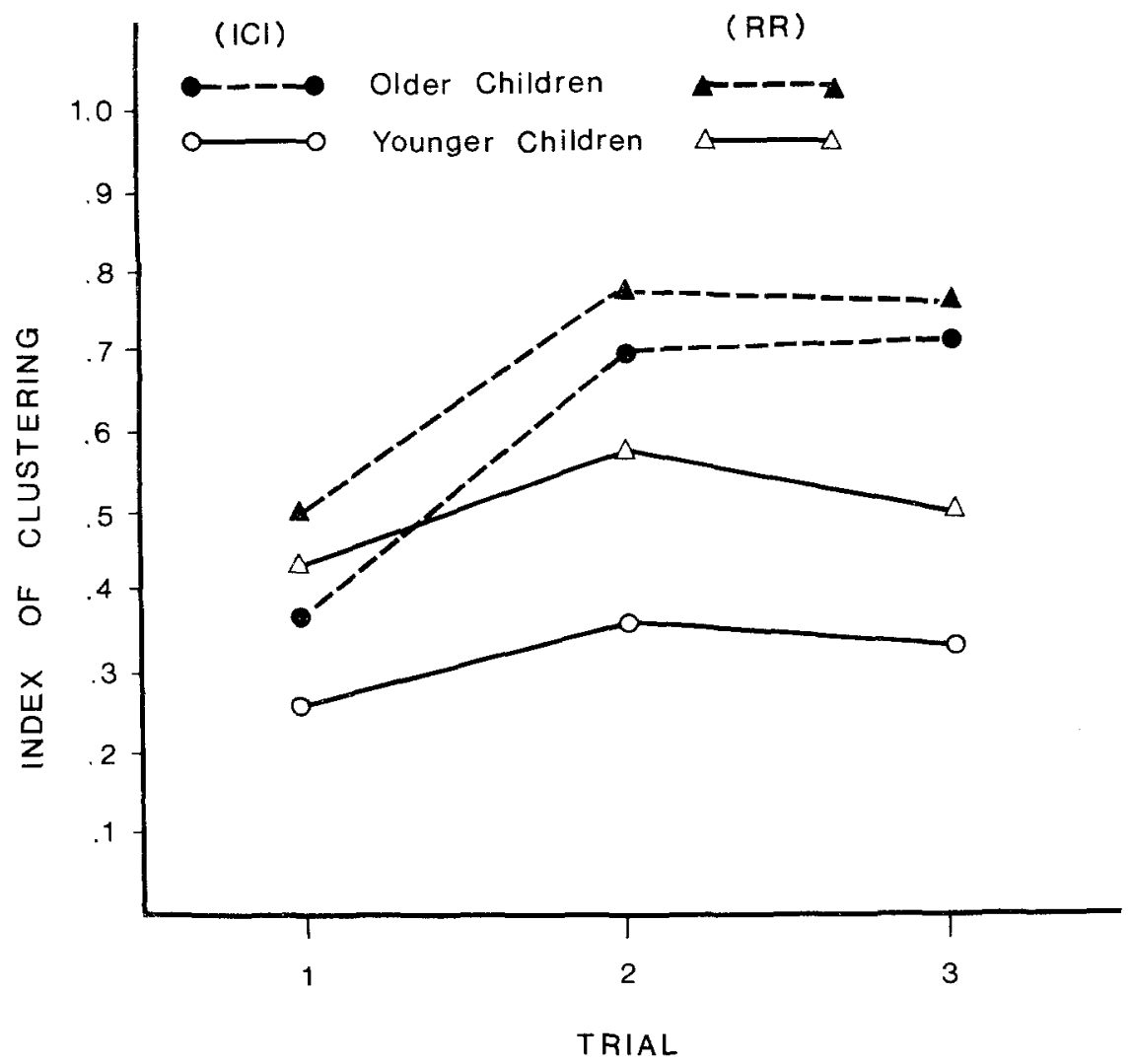

Figure 4. Use of clustering during recall as a function of trial and age.

dence intervals): clustering contrasted between the age groups at Trial 1-to-Trial 2 and at Trial 1-to-Trial 3. Overall, the older children used more clustering organization than the younger ones; organization increased after training; and the age advantage in clustering was most evident after training.

Individual comparisons of ICI, between ages, showed that the older children clustered more than the younger ones on Trial 2 and on Trial 3 (both $p$ 's $<.01$ ), but not on Trial 1. A training effect was evident only in the older children. Their increases in clustering from Trial 1-to-Trial 2 and from Trial 1-to-Trial 3 were both significant $[t(17)=4.85$ and $t(17)=5.74$, respectively, both $p$ 's $<.01]$. Further, what was learned was maintained and spontaneously employed in the third trial $[t(17)=.22$, n.s., for the Trial 2-to-Trial 3 change].

The results of the analyses using the RR clustering index were very similar to those of the ICI analyses. There was a main age effect $(p<.01)$ and a main 
trial effect ( $p<.01$ ); however, interaction approached, but did not reach statistical significance (see Table 1 and Figure 4). The mean RR score increased from .46 (out of 1.00 ) before training to .66 and .62 after training. In spite of the overall age and trial effects, individual comparisons of clustering, between ages, showed the older children performing better than the younger on Trials 2 and 3 (both $p$ 's $<.05$ ), but not on Trial 1 . Also similar to the result with the ICI index was evidence of a training effect only in the older children. Clustering increased for these children from Trial 1-to-Trial 2 and from Trial 1-to-Trial $3[t(17)=$ 5.36 and $t(17)=5.39$, respectively, both $p$ 's $<.01$. They maintained their performance on Trial $3 \grave{t}(17)=.28$, n.s., for Trial 2-to-Trial 3 change."

According to the ANOVAs, age played an important role in the increased use of organizational strategies in free recall, both in sorting and in clustering of words during recall. Without training, the older children showed just slightly more strategy usage than the younger ones. However, with training, the older children clearly clustered more than the younger, and the difference in sorting probably would have been even greater if the task had included more categories and/or items. Children at both ages improved significantly in sorting and maintained their new level of performance, but only the older children improved significantly in clustering during recall.

The older children of this study showed only slightly better recall than the younger prior to training. However, with training, the older ones tended to improve, and as a result they then recalled more items than did the younger. The 7- to 10-year olds consistently recalled only ten or eleven items. Contrary to findings from past studies (e.g., Neimark, Slotnick, \& Ulrich, 1971), the older children did not initially show significantly more strategy usage or better recall than the younger ones; the age advantage appeared only after the training session.

For the young children, it cannot be concluded that a simple production deficiency was exhibited because their use of sorting and clustering did not, in fact, result in improved recall. In the Torgesen (1977a) study, it was the physical sorting that differed between normal and learning disabled children, and which, when trained, was accompanied by improved recall. In the present study, training in sorting among the younger children resulted in improved performance in sorting but not in recall. Only on the younger children's final trial was there a significant correlation between sorting and recall $(r=.57, p<.01)$ and between clustering and recall $(r=.85, p<.01$ with $\mathbb{I C I})$. It may be the case that these children were developmentally "close" to the point of showing mediational facilitation.

For the older children, on the other hand, a production deficiency seems to have been evident in performance on the first trial, after which training was effective. When these children were left on their own, on Trial 3, not only was their recall maintained at the improved Trial 2 level, but also they continued to sort and cluster at the same relatively high level to which their use of strategies 
had risen in Trial 2. Among the older children, there is support for the conclusion that, when sorting and clustering are used, free recall improves. Whereas there was a significant correlation between sorting and recall on just the first trial $(r=$ $.48, p<.05$ ), the lack of correlations on the later trials is probably because of the ceiling effect on sorting on those trials. The correlations between clustering (ICI) and recall were $r=.70, .81$, and .70 (all $p$ 's $<.01$ ) on the three trials respectively. This synchronous response, in strategy use and concomitant recall, to the three-trial design of "baseline observation-intervention-observation" is supportive of both the sufficiency and necessity conditions that characterize the relationship between strategy use and recall as a production deficiency according to Paris (1978).

\section{Relationship Between Serial Recall and Free Recall}

Overall, the relationship between serial recall performance (central score) and free recall performance was $r=.34(p<.05), .49$, and $.49(p$ 's $<.01)$ on the three respective free recall trials. Since both memory tasks are visually presented tests of episodic memory, and both potentially benefit from strategies, the positive relationship found between them was anticipated.

The use of sorting on the second trial of free recall correlated with central recall $(r=.45, p<.01)$. Both clustering indices correlated with central recall on the two post-training trials $(p<.01$ for both ICIs and $p<.05$ for both RRs). When the children were trained in sorting and clustering, a positive relationship appeared between active strategy use in free recall and performance in serial recall. However, examination of Trial 1 of the free recall task, administered prior to any training, reveals that there was much room for improvement, among both the older and younger children, on all three measures. On this trial, performance appeared lacking, regardless of whether the children showed a mediation or a production deficiency. Corresponding to this baseline trial was their performance on the serial recall task in which there was no training employed: here, neither age group of children employed rehearsal. From this, it would appear that there is some evidence for a general description of these children as inactive on various memory tasks, at least in regard to strategies of rehearsal and organization.

\section{DISCUSSION}

In interpreting the results of this study, it should be kept in mind that this was a clinical sample of learning disabled children, not simply children chosen from a public school because of a discrepancy between academic achievement and potential. This type of sampling must be accompanied by obvious precautions in terms of generalization of research findings to a larger, less disabled population (for discussions about these methodological issues, see Torgesen, 1975; Warren, 
1978). However, such a clinical sample does ensure a certain amount of homogeneity because of the severity of their learning difficulties. It was expected that an understanding of mnemonic processes might be gained here that would not be seen as clearly in children with less severe difficulties.

The children in the present study showed no age difference in either sensory store performance (recency recall) or in non-strategic memory for incidental stimuli. These findings agree with past studies of learning disabled children of this age range in which there have been normal control subjects (Bauer, 1977, 1979; Tarver, et al., 1976). Neither the 7- to 10-year old nor the 11- to 13-year old group of learning disabled children showed evidence, through a primacy effect in serial recall, of an active rehearsal strategy. This is in contrast to the previous findings of primacy recall by around age 10 years in children with a learning disability, albeit of a less severe nature (Tarver, et al., 1976). Although without a direct test, it is assumed that our children had the ability to rehearse. However, either this strategy was not yet seen by them as useful for attaining a deliberate memory goal, or possibly they employed another encoding strategy at which the older ones were more proficient than the younger, but which did not differentiate first positions from later ones.

An interesting finding on the free recall task was the developmental trend from a mediation to a production deficiency. The direction of this progression is normal; however, it occurred here much later for these children. Non-disabled 7to 10-year olds clearly are expected to be beyond the level of a mediation deficiency on this type of task (e.g., Moely, 1977). The severity of the learning disabilities represented in the present study may well be related to the discrepant findings here of non-rehearsal and mediation deficiency.

Without interview data, we can only speculate that, prior to training, the 11-to 13-year old children did not realize the efficacy of the strategies they were capable of using. Training may have brought to them an awareness of the personal utility of the strategies (see Kennedy \& Miller, 1976). When they were then left on their own, coordinated strategy use and recall paralleled one another, in that they both were evidenced at relatively high levels. In further research, such a "remediated" production deficiency should be followed over time and across tasks, to explore its maintenance and generalization.

It is obvious from current literature that definitions of "learning disability" vary considerably from study to study. It is impossible at this time to draw definite conclusions about the validity of describing learning disabled children, in general, as inactive or inefficient learners. However, the present study has provided support for such a description of a clinical sample of children when presented with two episodic memory tasks. On the first task, the children did not actively rehearse. On the second, they did not automatically use organizational strategies to the extent that they could have. It would appear that this inactivity can and does change with age. Serial recall does improve as the children get older. This may be due to a later use of rehearsal, or to the use of some other 
encoding strategy which is available. In addition, older learning disabled children can easily learn to effectively sort and cluster so that free recall is improved.

The present study has examined memory strategies within a sample of children with learning disabilities, with the aim of determining if these children have unusual developmental characteristics. It is anticipated that extensions of this research could lead to individualized training efforts for the children's academic remediation.

\section{REFERENCES}

Atkinson, R. C., \& Shiffrin, R. M. Human memory: A proposed system and its control processes. In K. W. Spence \& J. T. Spence (Eds.), The psychology of learning and motivation: Advances in research and theory (Vol. 2). New York: Academic Press, 1968.

Bauer, R. H. Memory processes in children with learning disabilities: Evidence for deficient rehearsal. Journal of Experimental Child Psychology, 1977, 24, 415-430.

Bauer, R. H. Memory, acquisition, and category clustering in learning-disabled children. Journal of Experimental Child Psychology, 1979, 27, 365-383.

Cohen, B. H., Sakoda, J. M., \& Bousfieid, W. A. The statistical analysis of the incidence of clustering in the recall of randomly arranged associates (Tech. Report No. 10). University of Connecticut, Contract Nonr. 631 (00), Office of Naval Research, July 1954 (NTIS No. PB-117628),

Colle, H. A. The reification of clustering. Joumal of Verbal Learning and Verbal Behavior, 1972 , $H, 624-633$.

Flavell, J. H. Developmental studies of mediated memory. In H. W. Reese \& L. P. Lipsiti (Eds.), Advances in child development and behavior (Vol. 5). New York: Academic Press, 1970.

Hagen, J. W., \& Kingsley, P. R. Labeling effects in short-term memory. Child Development, 1968, $39,113-121$.

Hagen, J. W., \& Stanovich, K. E. Memory: Strategies of acquisition. In R. V. Kail \& J. W. Hagen (Eds.), Perspectives on the development of memory and cognition. Hillsdale, NJ: Erlbaum, 1977.

Hagen, J. W., Jongeward, R. H., \& Kail, R. V. Cognitive perspectives on the development of memory. In H. W. Reese (Ed.), Advances in child development and behavior (Vol. 10). New York: Academic Press, 1975.

Johnson, D. J., \& Myklebust, H. R. Learning disabilities: Educational principles and practices. New York: Grune \& Stratton, 1964.

Kennedy, B. A., \& Miller, D. J. Persistent use of verbal rehearsal as a function of information about its value. Child Development, 1976, 47, 566-569.

Moely, B. E. Organizational factors in the development of memory. In R. V. Kail \& J. W. Hagen (Eds.), Perspectives on the development of memory and cognition. Hillsdale, NJ: Erlbaum, 1977.

Moely, B. E., Olson, F. A., Halwes, T. G., \& Flavell, J. H. Production deficiency in young children's clustered recall. Developmental Psychology, 1969, 1, 26-34.

Murphy, M. D. Measurement of category clustering in free recall. In C. R. Puff (Ed.), Memory organization and struciure. New York: Academic Press, 1979.

Murphy, M. D., Campione, J. C., \& Puff, C. R. Measures of category clustering in free recall. Paper presented at the biennial meetings of the Society for Research in Child Development, New Orleans, 1977.

Niemark, E., Slotnick, N. S., \& Ulrich, T. Development of memorization strategies. Developmental Psychology, 1971, 5, 427-432. 
Paris, S. G. Coordination of means and goals in the development of mnenomic skills. In P. Ornstein (Ed.), Memory development in children. Hilisdale, NJ: Erlbaum, 1978.

Parker, T., Freston, C., \& Drew, C. Comparison of verbai performance of normal and learning disabled children as a function of input organization. Journal of Learning Disabilities, 1975, $8,53-60$.

Robinson, J. A. Category clustering in free recall. Journal of Psychology, 1966, 62, 279-285.

Tarver, S. G., Hallahan, D. P., Cohen, S. B., \& Kauffman, J. M. The development of visual selective attention and verbal rehearsal in learning disabled boys. Journal of Learning Disabilities, 1977, 10(8), 491-500.

Tarver, S. G., Hallahan, D. P., Kauffman, J. M., \& Ball, D. W. Verbal rehearsal and selective attention in children with learning disabilities: A developmental lag. Journal of Experimental Child Psychology, 1976, 22, 375-385.

Torgesen, J. K. Problems and prospects in the study of learning disabilities. In E. M. Hetherington (Ed.), Review of child development research. Chicago: University of Chicago Press, 1975.

Torgesen, J. K. Memorization processes in reading-disabled children. Journal of Educational Psychology, 1977, 69, 571-578.(a)

Torgesen, J. K. The role of non-specific factors in the task performance of learning disabled children: A theoretical assessment. Journal of Learning Disabilities, 1977, 10, 33-40. (b)

Torgesen, J. K., \& Goldman, T, Verbal rehearsal and short-term memory in reading-disabled children. Child Development, 1977, 48, 56-60.

Torgesen, J. K., \& Kail, R. V., Jr. Memory processes in exceptional children. In B. Keogh (Ed.), Advances in special education (Vol. 1). Greenwich, Conn: JAI Press, in press.

Warren, D. H. Childhood visual impairment: Perspectives on research design and methodology. Visual tmpairment and Blindness, December 1978, 404-411. 